\title{
Differential susceptibility of pine weevil, Hylobius abietis (Coleoptera: Curculionidae), larvae and pupae to entomopathogenic nematodes and death of adults infected as pupae
}

\author{
Christopher D. Williams • Aoife B. Dillon • \\ Darragh Ennis • Roseanne Hennessy • \\ Christine T. Griffin
}

Received: 14 October 2014/ Accepted: 29 January 2015

(c) International Organization for Biological Control (IOBC) 2015

\begin{abstract}
The large pine weevil Hylobius abietis is a serious pest of reforestation in northern Europe. Development takes place in the stumps of felled conifer trees and emerging adults feed on and kill newly planted trees. Application of entomopathogenic nematodes around tree stumps has been shown to reduce the emergence of adult weevils. In order to target application at the most susceptible stage, the susceptibility of larvae and pupae to Heterorhabditis downesi and Steinernema carpocapsae was compared in a close-contact assay on filter paper. An average of $95.8 \%$ of larvae were killed by $H$. downesi and $82.1 \%$ by $S$. carpocapsae while only 16.3 and $15.0 \%$ of pupae were killed by these two species, respectively. However, many of the H. abietis that were exposed as pupae died after metamorphosis to callow adult, with mortality of pupae and callow adults combined reaching $62.5 \%$ for $H$. downesi and $69.9 \%$ for $S$. carpocapsae. For both nematode species significantly more insects died as larvae than as either pupae or
\end{abstract}

Handling Editor: Ralf Ehlers.

C. D. Williams $(\bowtie) \cdot$ A. B. Dillon · D. Ennis ·

R. Hennessy · C. T. Griffin

Department of Biology, Maynooth University, Maynooth,

Co. Kildare, Ireland

e-mail: chris.david.williams@gmail.com

R. Hennessy

Teagasc Kinsealy Research Station, Kinsealy, Co. Dublin, Ireland pupae/callow adults. When pupae were exposed to infective juveniles (IJs) for 2 days and were then washed while still pupae to remove surface IJs, adults were later found to be infected indicating that IJs can infect pupae, survive metamorphosis and subsequently kill adults.

Keywords Pine weevil - Entomopathogenic nematodes - Differential susceptibility · Forest pests · Biocontrol

\section{Introduction}

The large pine weevil, Hylobius abietis (L.) (Coleoptera: Curculionidae), is the most serious pest of reforestation in Europe, costing the forestry sector millions of euro per annum e.g. $€ 2.57$ million $(\$ 3.36$ million) a year in the UK and up to $€ 30$ million ( $\$ 38.84$ million) annually in Sweden (Weslien 1998; Leather et al. 1999; Långström and Day 2004). If no chemical control measures were used against the pine weevil, the most recent estimate for the economic damage that would result across Europe was $€ 140$ million (\$181.26 million) per annum (Långström and Day 2004). Adult weevils are attracted to volatile chemical cues which are emitted when coniferous trees are felled. Females oviposit in the stump and larvae and pupae develop in or under the bark (Leather et al. 1999) often below soil level at depths in excess of $20 \mathrm{~cm}$. On emergence, 
adults feed on the bark of young trees planted on the clearfelled site, which can result in death through 'ring barking'. Without control measures, weevils can destroy up to $100 \%$ of newly planted trees, with a UK national average estimate of $50 \%$ mortality within the first few years at untreated sites (Heritage and Moore 2001).

Current control measures include the synthetic chemicals alpha cypermethrin or cypermethrin, which are administered in nursery pre-treatment either via electrodyne application or dipping of saplings prior to planting and/or through on-site post-planting spray. However, with concerns over potential environmental impacts, cypermethrin is being phased out across Europe (EC 2012). Also, under Forest Stewardship Council (FSC) guidelines, alpha cypermethrin and cypermethrin are considered "highly hazardous chemicals" applied only under derogation, so there is an obligation on FSC certified companies to find alternatives to chemical control. Furthermore, current pesticides have a repellent effect on the pine weevil and, while this protects young plants, it does little to impact on the local populations of the pest (Torr et al. 2005; Leather et al. 1999).

Entomopathogenic nematodes (EPN) have been used as a sustainable method of controlling pine weevils (Torr et al. 2005; Dillon and Griffin 2008). Nematodes are applied as inundative biological control agents (biopesticides) targeted against pine weevil larvae, pupae and callow adults developing within the stumps. We have previously shown that Heterorhabditis downesi (Stock, Griffin and Burnell) was best at controlling this subterranean cryptic pest, but Steinernema carpocapsae (Weiser) was also effective (Dillon et al. 2006). At operational level, S. carpocapsae is applied by pressure hose, from a tank mixer mounted on a modified forwarder, at an average rate of 3.5 million nematodes per stump (Torr et al. 2005). These operations are conducted by growers in the UK and Ireland, mainly the Forestry Commission and Coillte, respectively.

In field trials the various life stages of $H$. abietis differed in susceptibility to EPN infection. Dillon et al. (2006) found that $45 \%$ of larvae, $32 \%$ of pupae and $30 \%$ of adults in stumps were infected by EPN when assessed 4 weeks after nematode application. However, uninfected larvae and pupae may have gone on to develop into pupae and adults, respectively. Brixey et al. (2006) adjusted for this and estimated that $14 \%$ of larvae, $13 \%$ of pupae and $44 \%$ of callow adults were infected by $S$. carpocapsae after application to stumps. In laboratory trials on a cotton substrate Pye and Burman (1978) found that larvae were more susceptible—between 80 and $95 \%$ were killed by $S$. carpocapsae with no pupae and only $5 \%$ of adults killed. In contrast, Brixey (2000) reported that pupae were more susceptible than late instar (4-5th instar) larvae, and Torr et al. (2005) recommended targeting pupae.

The aim of the present study is to assess the susceptibility of various life stages of $H$. abietis to EPN infection; larvae and pupae of $H$. abietis were indefinitely exposed to various concentrations of $S$. carpocapsae and $H$. downesi in a close contact assay on filter paper. A second aim of the present paper is to determine whether infective juveniles (IJs) may infect pupae, survive metamorphosis and subsequently kill newly eclosed adults.

\section{Materials and methods}

Source of weevils and nematodes; culturing of nematodes

Pine weevil larvae and pupae were collected from clear-felled forest sites by removing the bark of lodgepole pine (Pinus contorta Douglas) with a chisel and collecting immature weevils from their galleries. The following nematode isolates were used: $S$. carpocapsae (US-S-25 from Koppert), S. carpocapsae (All strain) and H. downesi (K122).

Stocks of nematodes were cultured in the laboratory using Galleria mellonella (L.) larvae which were placed on White traps (White 1927) and harvested IJs were washed by sedimentation in tap water (Kaya and Stock 1997). Nematodes were stored at $9{ }^{\circ} \mathrm{C}$ and were used within 2 weeks.

Susceptibility of Hylobius abietis larvae and pupae to infection by $S$. carpocapsae and $H$. downesi on filter paper

Late instar larvae and pupae of $H$. abietis were placed in $1.5 \mathrm{~cm}$ diameter wells of 24-well tissue culture plates that had been lined with one $1 \mathrm{~cm}$ diameter disc of filter paper. Each insect was then treated with either S. carpocapsae (US-S-25 Koppert strain) or $H$. 
downesi (K122 strain) applied to the filter paper in $50 \mu \mathrm{l}$ of water. Control treatments for both larvae and pupae had $50 \mu \mathrm{l}$ of water applied to the filter paper. The insects were then incubated at $20^{\circ} \mathrm{C}$ and, at intervals checked for mortality and the life stage at time of death was noted. There were four experiments:

- In experiment 1 , the concentrations used were 25 , 50,100 , or $200 \mathrm{IJ}$ s for larvae and for pupae. There were 24 insects in each treatment. Mortality and life stage were checked daily for 2 weeks.

- In experiment 2, there were just two concentrations of each nematode species, 50 and 250 IJs for both larvae and pupae. Each treatment was replicated three times with 24 insects in each replicate (total 72 insects). Mortality and life stage was recorded on days 5, 8, 13 and 19.

- Experiment 3 tested pupae only, and included higher nematode concentrations: 250, 1,000 and 2,000 IJs. There were 24 insects per treatment. Mortality and life stage were recorded daily for 18 days. The aim was to test whether a higher concentration of nematodes would result in higher mortality of pupae as pupae rather than as callow adults.

- For experiment 4 , a small number of insects (12 per treatment) that had pupated within the previous $24 \mathrm{~h}$ were exposed to a single concentration of 2,000 IJs.

Washing experiment to determine whether IJs infecting pupae can cause death following metamorphosis

As we observed that some of the insects exposed to nematodes as pupae died as adults we tested the hypothesis that IJs might enter weevil larvae in the pupal stage, survive metamorphosis and then kill the weevil in the adult stage. To do this we performed a washing experiment. Weevil pupae were exposed to IJs of either H. downesi (K122 strain) or S. carpocapsae (All strain) (250 IJs) on filter paper in multi-well plates, as above. After 2 days' exposure, weevils were either washed clean of IJs by dipping them in tap water, or were left in contact with the nematode-contaminated filter paper. Washed insects were examined under a dissecting microscope to confirm the absence of visible IJs, and each was then placed in a clean multiwell with moist filter paper. The experiment was repeated four times, with 10-12 insects per treatment in each experiment. Weevil mortality and stage were recorded daily. Weevils were observed for 1 month following washing. Dead weevils were dissected to confirm infection by nematodes.

Statistical analysis

$T$ tests, Mann-Whitney U tests, $\chi^{2}$ tests and Probit analysis were all performed on the statistical package Minitab version 16.

\section{Results}

Susceptibility of Hylobius larvae and pupae to $S$. carpocapsae and $H$. downesi on filter paper

\section{Larvae}

The lowest mortality of pine weevil larvae was $62.5 \%$ (50 S. carpocapsae IJS per insect in experiment 2); all other treatments 25-250 S. carpocapsae or H. downesi IJS per insect killed at least $80 \%$ of the exposed larvae (Table 1). Thus, the $\mathrm{LC}_{50}$ for each species is $<25 \mathrm{IJS}$ per insect. Overall, more larvae were killed by $H$. downesi than by $S$. carpocapsae (Paired $t$ test, $\mathrm{t}=2.71$, df $=5, P=0.042)($ Table 1$)$.

As regards the speed of kill, in experiment 1, larvae exposed to H. downesi showed high mortality by day 5 , but larvae exposed to $S$. carpocapsae continued to die up to day 13. For the highest concentration (200 IJS per insect) the $\mathrm{LT}_{50}$ (with fiducial limits) for $H$. downesi was 3.4 (3.0-3.6) days and for $S$. carpocapsae was 4.4 (3.6-5.0) days (data not shown); a marginally significant difference (based on the fact that the fiducial limits just overlap), with $H$. downesi killing more quickly than $S$. carpocapsae. Similarly in experiment 2, larvae continued to die up to day 13 in all treatments, with death in the lower concentrations of those larvae treated with $S$. carpocapsae continuing for longer-up to day 19 when the experiment was terminated (Fig. 1a).

\section{Pupae}

In experiment 1 , mortality for insects exposed as pupae ranged from 45.8 to $100 \%$ but there was no consistent concentration response over the range of 


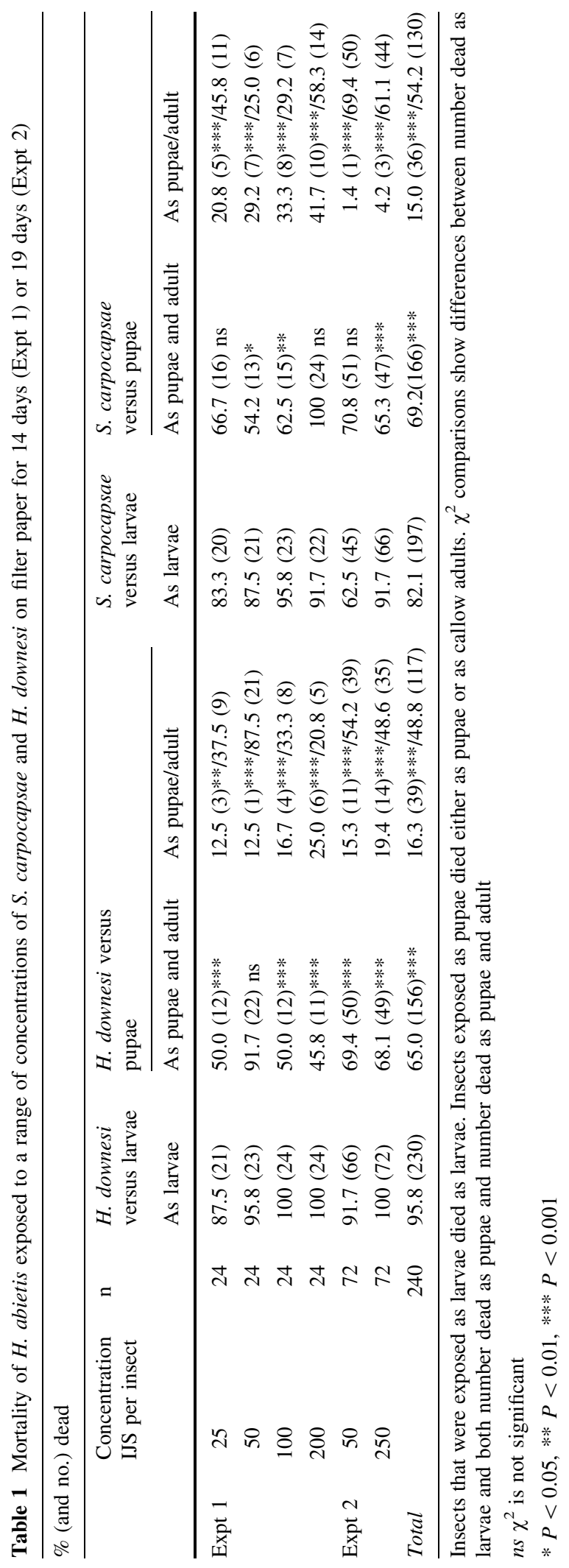


Fig. 1 Experiment 2.

Mortality (number of insects $\mathrm{dead} / 24$, mean of three replicates) of Hylobius abietis exposed to EPN as larvae (a) and as pupae (b). $\mathrm{Hd}=$ Heterorhabditis downesi, $\mathrm{Sc}=$ Steinernema carpocapsae, numbers in legend represent number of infective juveniles applied. Error bars represent $\pm \mathrm{SE}$
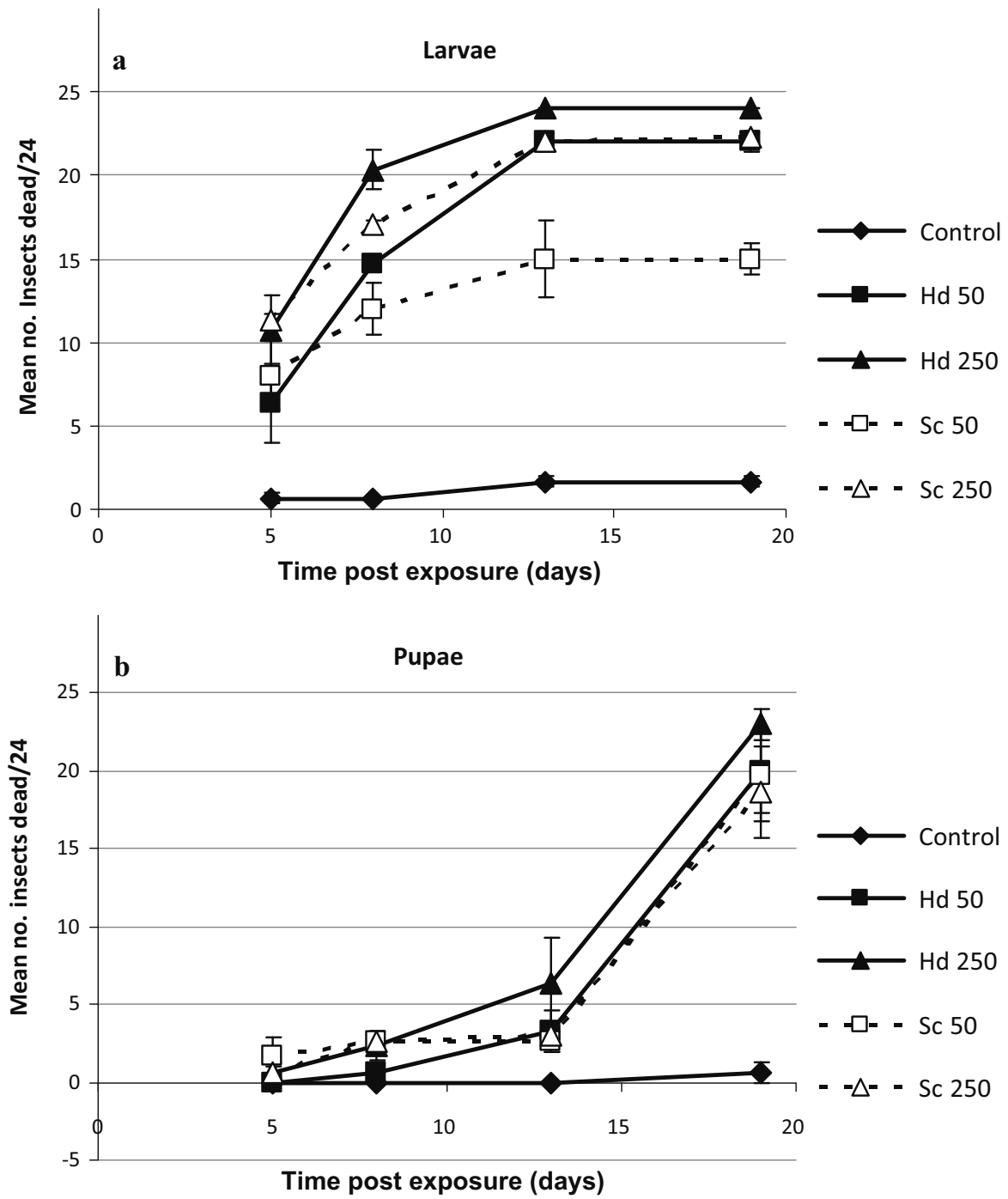

concentrations tested (25-200 IJs per insect) (Table 1). Most of the insects exposed as pupae died as callow adults (Table 1). Insects exposed as pupae continued to die until the experiment was terminated on day $13 . \mathrm{LT}_{50} \mathrm{~S}$ were not calculated for pupae, since most of the deaths occurred as adults.

Experiment 2 showed broadly similar results with most of the insects that died following exposure of pupae to nematodes dying as callow adults (Table 1). The death of these newly eclosed adults explains the steep increase in mortality in Fig. 1b. The total mortality (pupae and callow adults) was similar for both nematode species (Table 1).

In experiment 3 , the maximum mortality of pupae was $75 \%$ (exposed to 2,000 H. downesi per insect)
(Table 2). In experiment 4, when newly developed pupae (within 24 h of pupation) were exposed to 2,000 nematodes, more than $80 \%$ were killed (H. downesi $10 / 12=83.3 \% ;$ S. carpocapsae, $11 / 12=91.7 \%)$, a significant difference to the older pupae of experiment 3 exposed to the same concentration of $S$. carpocapsae $\left(\chi^{2}=6.02, \mathrm{df}=1, P=0.014\right)$, but not $H$. downesi $\left(\chi^{2}=0.321\right.$, df $\left.=1, P=0.571\right)$.

\section{Larvae versus pupae}

Considerably more larvae than pupae were killed at all concentrations of both nematode species in each of the two experiments, and the difference was highly significant (e.g. $\chi^{2}=14.187 \mathrm{df}=1, P<0.001$ ) in 
Table 2 Mortality of $H$. abietis exposed to a range of concentrations of $S$. carpocapsae and $H$. downesi on filter paper

\begin{tabular}{|c|c|c|c|c|c|c|c|c|}
\hline \multirow[t]{3}{*}{ Expt } & \multirow{3}{*}{$\begin{array}{l}\text { Concentration } \\
\text { IJS per insect }\end{array}$} & \multirow[t]{3}{*}{$\mathrm{n}$} & \multicolumn{6}{|l|}{$\%$ (and no.) dead } \\
\hline & & & \multicolumn{3}{|l|}{ H. downesi } & \multicolumn{3}{|l|}{ S. carpocapsae } \\
\hline & & & As pupae and adult & As pupae & As adult & As pupae and adult & As pupae & As adult \\
\hline \multirow[t]{3}{*}{3} & 250 & 24 & $87.5(21)$ & $29.2(7)$ & $58.3(14)$ & $100(24)$ & $50.0(12)$ & $50.0(12)$ \\
\hline & 1,000 & 24 & $100(24)$ & $12.5(3)$ & $87.5(21)$ & 79.2 (19) & $45.8(11)$ & $33.3(8)$ \\
\hline & 2,000 & 24 & $100(24)$ & $75.0(18)$ & $25.0(6)$ & $95.8(23)$ & $50.0(12)$ & $45.8(11)$ \\
\hline 4 & 2,000 & 12 & $100(12)$ & $83.3(10)$ & $16.7(2)$ & $100(12)$ & $91.7(11)$ & $8.3(1)$ \\
\hline Total & & 84 & $96.4(81)$ & $45.2(38)$ & $51.2(43)$ & $92.9(78)$ & $54.8(46)$ & $38.1(32)$ \\
\hline
\end{tabular}

Pupae in experiment 4 had been prepupae at most $24 \mathrm{~h}$ while those in experiment 3 were older

each case (Table 1). On average, 16.9 and $21.8 \%$ of pupae died as pupae when exposed to H. downesi and $S$. carpocapsae, respectively, compared to 95.8 and $82.1 \%$ of larvae. However, additional insects died following metamorphosis to callow adult, with mortality reaching 62.5 and $69.9 \%$ of insects exposed as pupae/callow adults to $H$. downesi and $S$. carpocapsae, respectively. There was no significant difference between those infected with $H$. downesi and those infected with $S$. carpocapsae (paired $t$ test, $\mathrm{t}=-0.61$, $\mathrm{df}=5, P=0.570$ ). The difference between mortality of larvae and that of pupae plus callow adults combined was still significant in most cases (Table 1).

\section{Washing experiment}

In the washing experiment $11.3-27.5 \%$ of the weevils died as pupae, but also an additional 15.0-32.5\% died as adults (Table 3). Some weevils that died as adults were callow adults and others were fully sclerotized. In cases where adults died following washing (Table 3), this indicates that IJs can survive metamorphosis within weevil pupae and can subsequently kill adults. This may take place anytime between 4 and 13 days from exposure of weevils to nematodes. There was no significant difference in percentage infectivity between "washed" and "unwashed" treatments for pupae or adults of either species $(P>0.05$ for all four Mann-Whitney U tests-see Table 3). Furthermore, washing had no effect on the proportion of infected insects that died as adults for either species $(H$. downesi: $\chi^{2}=0.776$, df $=1, P=0.379 ;$ S. carpocapsae: $\chi^{2}=1.802$, df $\left.=1, P=0.179\right)$. Overall, adults accounted for $70.0 \%$ of the "washed" insects killed and infected by $H$. downesi and $35.3 \%$ of the insects killed and infected by $S$. carpocapsae. All dissected adults infected with nematodes had second generation adult nematodes present. For those infected with $S$. carpocapsae this means at least two IJs entered each pupa. Since $H$. downesi are hermaphrodite in the first generation only a single IJ had to enter each pupa.

For those insects that died as adults, the time from washing ( 2 days after initial exposure) to death of adults ranged from 2 to 11 days. This is divided into two periods-the time from washing to eclosion, which gives a measure of the age of the pupae, and the time from eclosion to death, which gives an indication of the speed at which nematodes killed adults, assuming that the process began at eclosion. The time between washing and eclosion of adults had a median (range given in parentheses) of 1 (1-4) days and 4 (1-9) days for $H$. downesi and $S$. carpocapsae infected individuals, respectively and the time between eclosion of adults and death had a median of 2 (1-5) days and 4 (2-5) days for $H$. downesi and $S$. carpocapsae infected individuals, respectively. The time between eclosion and death of adults was significantly longer in those insects infected with $S$. carpocapsae compared to those infected with $H$. downesi (Mann-Whitney $\mathrm{U}$ test: $\mathrm{W}=78, P=0.034)$.

\section{Discussion}

The susceptibility of insects, including beetles, to EPN often changes with life stage. The susceptibility of Chrysomelidae is sometimes higher in the larval stage (Saleh et al. 2009), sometimes in the pupal stage $(\mathrm{Xu}$ et al. 2010) and which stage is more susceptible is sometimes dependent on temperature (Yang et al. 
Table 3 Percentage (mean \pm SE) of Hylobius abietis dead and infected by entomopathogenic nematodes as either pupae or adults

\begin{tabular}{llll}
\hline Species & Treatment & As pupae & As adults \\
\hline Heterorhabditis downesi & Unwashed & $15.8 \pm 7.11$ & $19.2 \pm 10.83$ \\
& Washed & $11.3 \pm 6.57$ & $26.3 \pm 4.73$ \\
Steinernema carpocapsae & Unwashed & $27.5 \pm 11.81$ & $32.5 \pm 16.52$ \\
& Washed & $27.5 \pm 13.77$ & $15.0 \pm 5.00$ \\
\hline
\end{tabular}

Pupae were exposed to 250 nematode infective juveniles for two days and were then either washed free of surface nematodes or were left unwashed. Infection was confirmed by dissection. There were no significant differences between washed and unwashed treatments (Mann-Whitney $\mathrm{U}$ test $P>0.05$ for all four tests). $\mathrm{N}=4$ experiments

2003). For the Scarabaeidae both Lacey et al. (2001) and Khatri-Chhetri et al. (2011) found that pupae were more susceptible than larvae to EPN. Ramos-Rodríguez et al. (2006) found EPN were less efficacious against pupae and adults than larvae of Tribolium castaneum.

Among the weevils (Curculionidae), however, Loya and Hower (2003), Jansson et al. (1990), Abbas et al. (2001) and Mannion and Jansson (1992) demonstrated a higher susceptibility of larvae compared to pupae. Thus, whereas it may be difficult to draw general conclusions as to the susceptibility of different beetle stages to nematodes, the Curculionidae, at least, all appear to have more resistant pupal than larval stages. Our data show that pine weevil larvae are more susceptible than pupae to both $S$. carpocapsae and $H$. downesi. Furthermore, for $H$. downesi, we show that most deaths that occur following exposure of pupae do so following metamorphosis. As they were continually exposed in the initial set of experiments we do not know whether they were infected as pupae, as callow adults or both. Most studies, however, do not report whether deaths of insects exposed in the pupal stage occur before or after metamorphosis, and it may be that such a phenomenon is common among the Curculionidae. We conclude that applying nematodes to stumps earlier after felling to target Hylobius larvae, in contrast to Brixey et al. (2006) and Torr et al. (2005) recommendations, may be more efficacious in controlling pine weevil. Brixey (2000) found that pupae were about twice as susceptible as late instar larvae. It is unclear why Brixey produced different results to us.

The results of our washing experiment indicate that IJs may infect pupae and then survive metamorphosis and subsequently kill adults (either callow adults or fully sclerotized adults) following eclosion from the pupa. The fact that washing had no effect on the proportion of infected insects that died as adults, for either species, is exactly the result one would predict if nematodes were invading pupae and surviving metamorphosis within the weevil. Other parasites have been known to survive metamorphosis in amphibians such as the intestinal nematode Oswaldocruzia filiformis in Rana temporaria temporaria (Griffin unpublished), but this is, to our knowledge, the first report of such a phenomenon in entomopathogenic nematodes and insects. It is possible that IJs entering pupae are first encapsulated, but during metamorphosis in which tissues are extensively destroyed and remodelled (Richards and Davies 1977) they are subsequently freed from encapsulation and are at liberty to kill adult weevils. Encapsulation is a common immune response among insects, and encapsulation of EPN has been reported in H. abietis larvae and adults (Pye and Burman 1977; Girling et al. 2010). However, nematodes may escape encapsulation ( $\mathrm{Li}$ et al. (2007). Girling et al. (2010) found that live adult $H$. abietis harboured encapsulated or dead nematodes and these weevils may have successfully defended themselves against the nematodes and might have survived had they not been sacrificed. Other live weevils sacrificed at the time ( 5 days post exposure) harboured live nematodes instead (Girling et al. (2010), which may either have escaped from encapsulation or evaded it in the first place but had not yet killed the insect. Another possible explanation for the results of our washing experiment is that IJs wait in the intestine or tracheal system of pupae free from encapsulation. Further research is required to decide between these two hypotheses. Either of these scenarios (surviving for days as IJ without killing the host) may reflect the evolutionary origins of EPN as necromenics (where dauer juveniles wait for a host to die naturally before commencing feeding) (Sudhaus 2008). 
In our experiments the time between washing and eclosion of adults was generally low (median values of 1 and 4 days) showing that most weevils were fairly well advanced as pupae prior to infection with nematodes. However, the range of values was quite high (up to 9 days) showing that pupae can be infected when they are much younger, and can be subsequently killed as adults. The pupal stage of $H$. abietis should last for 17.2 days at $20{ }^{\circ} \mathrm{C}$, based on the thermal constants provided by Inward et al. (2012). The fact that the time to death after eclosion was significantly longer for $S$. carpocapse compared to $H$. downesi reflects the situation in the larval experiments, where H. downesi also killed somewhat faster than $S$. carpocapsae.

Girling et al. (2010) showed that mortality of adult pine weevil at relatively high concentrations of IJs (500 and 4,000) of S. carpocapsae and H. downesi was lower than the mortality of larvae and pupae caused by the same EPN species reported here, even at lower concentrations. As we show that the larvae are the most susceptible stage, field application of nematodes earlier in the season when a high proportion of pine weevil are in this stage is likely to be more efficacious than later in the season when the proportion of pupae and callow adults is higher. It should be noted that IJs applied to target larvae may persist or may recycle through hosts and also kill pupae and callow adults even when they are applied earlier in the season.

With other EPN species and/or hosts there may be an EPN-host stage interaction as Ramos-Rodriguez et al. (2006) found for T. castaneum. However, when testing nematode efficacy against pine weevil under field conditions, Dillon et al. (2006) found no such interaction of weevil stage $\times$ nematode species, and this is supported by the laboratory experiments reported here as both $H$. downesi and $S$. carpocapsae were more effective against larvae than against later stages. There are many possible reasons for the different susceptibilities between life stages. Activity and attraction of nematode IJs to active, feeding larvae (Lewis et al. 1992) may be higher than to the inactive pupae, there may be greater possibilities of IJ entry into larvae compared to pupae, or the stages may differ in their immune response.

$\mathrm{LT}_{50}$ values and times to death have been widely reported for S. carpocapsae. Grewal et al. (1993) report the species killing the wax moth (G. mellonella) within $24 \mathrm{~h}$ and Feng et al. (2006) report slightly longer $\mathrm{LT}_{50} \mathrm{~s}$ of between 26 and $27.25 \mathrm{~h}$ depending on long-term storage conditions. Saleh et al. (2009) reported $\mathrm{LT}_{50} \mathrm{~s}$ of around $37 \mathrm{~h}$ for larvae of the sugar beet beetle (Cassida vittata) exposed to $S$. carpocapsae and Schroer et al. (2005) reported an $\mathrm{LT}_{50}$ of $<25 \mathrm{~h}$ for the diamondback moth (Plutella xylostella) when exposed to $S$. carpocapsae and adjuvants. Other insects are more resistant, with cockroaches taking a particularly long time to kill (Appel et al. 1993; Koehler et al. 1992). Our $\mathrm{LT}_{50}$ s for late larval instars of $H$. abietis ( $\sim 4$ days) are close to the upper range of those reported in the literature.

Our close-contact bioassay results show a similar pathogenicity for both $H$. downesi and $S$. carpocapsae. However, Dillon et al. $(2006,2007)$ and Williams et al. (2013a, b) showed conclusively that $H$. downesi is more efficacious than $S$. carpocapsae against pine weevil in the field as assessed by both emergence of adult weevils and by infection data gleaned from destructive sampling of stumps. We suggest that the difference between our close-contact bioassay results and the previously reported field results are due to the different foraging strategies, which are thought to be employed by the two species (Lewis et al. 1992; Grewal et al. 1994). Heterorhabditis downesi is described as a "cruise" forager whereas $S$. carpocapsae is described as a typical "ambush" forager, though there is some evidence that $S$. carpocapsae can cruise forage in organic substrates (Kruitbos et al. 2010). Such differences in foraging strategies are probably not important in close-contact bioassays, but would be important under field conditions where weevil hosts must first be located prior to infection.

Acknowledgments The work was financially supported by the European Regional Development Fund (INTERREG IVA) administered through the Welsh European Funding Office (IMPACT project), and by the Irish National Development Plan through COFORD, the National Council for Forest Research and Development (ABATE project). RH was supported by a Teagasc Walsh Fellowship.

\section{References}

Abbas MST, Saleh MME, Akil AM (2001) Laboratory and field evaluation of the pathogenicity of entomopathogenic nematodes to the red palm weevil, Rhynchophorus ferrugineus (Oliv.) (Col.: Curculionidae). J Pest Sci 74(6):167-168

Appel AG, Benson EP, Ellenberger JM, Manweiler SA (1993) Laboratory and field evaluations of an entomogenous 
nematode (Nematoda: Steinernematidae) for German cockroach (Dictyoptera: Blattellidae) control. J Econ Entomol 86:777-784

Brixey JM (2000) The use of entomopathogenic nematodes to control the immature stages of the large pine weevil, $\mathrm{Hy}$ lobius abietis L. (Unpublished doctoral dissertation), The University of Reading, Reading

Brixey JM, Moore R, Milner ADJ (2006) Effect of entomopathogenic nematode (Steinernema carpocapsae Weiser) application technique on the efficacy and distribution of infection of the large pine weevil (Hylobius abietis L.) in stumps of Sitka spruce (Picea sitchensis Carr.) created at different times. For Ecol Manage 226:161-172

Dillon A, Griffin C (2008) Controlling the large pine weevil, Hylobius abietis, using natural enemies. Silviculture/ Management No. 15. Coford Connects, Dublin

Dillon A, Ward D, Downes MJ, Griffin CT (2006) Suppression of the large pine weevil Hylobius abietis (L.) (Coleoptera: Curculionidae) in pine stumps by entomopathogenic nematodes with different foraging strategies. Biol Control 38:217-226

Dillon AB, Downes MJ, Ward D, Griffin CT (2007) Optimizing application of entomopathogenic nematodes to manage large pine weevil Hylobius abietis L. (Coleoptera: Curculionidae) populations developing in pine stumps, Pinus sylvestris. Biol Control 40:253-263

EC (2012) Proposal for a revised directive of the European parliament and of the council on priority substances in the field of water quality. Memo 12/59

Feng S-P, Han R-C, Qui X-H, Cao L, Chen J-H, Wang G-H (2006) Storage of osmotically treated entomopathogenic nematode Steinernema carpocapsae. Insect Sci 13:263-269

Girling RD, Ennis D, Dillon AB, Griffin CT (2010) The lethal and sub-lethal consequences of entomopathogenic nematode infestation and exposure for adult pine weevils, $H y$ lobius abietis (Coleoptera: Curculionidae). J Invertebr Pathol 104:195-202

Grewal PS, Gaugler R, Kaya HK, Wusaty M (1993) Infectivity of the entomopathogenic nematode Steinernema scapterisci (Nematoda: Steinernematidae). J Invertebr Pathol 62:22-28

Grewal PS, Lewis EE, Gaugler R, Campbell JF (1994) Host finding behaviour as a predictor of foraging strategy in entomopathogenic nematodes. Parasitology 108:207-215

Heritage S, Moore R (2001) The assessment of site characteristics as part of a management strategy to reduce damage by Hylobius. Forestry Commission Information Note 38. HMSO, UK

Inward DJG, Wainhouse D, Peace A (2012) The effect of temperature on the development and life cycle regulation of the pine weevil Hylobius abietis and the potential impacts of climate change. Agric For Entomol 14:348-357

Jansson RK, Lecrone SH, Gaugler RR, Smart GC Jr (1990) Potential of entomopathogenic nematodes as biological control agents of sweet potato weevil (Coleoptera: Curculionidae). J Econ Entomol 83:1818-1826

Kaya HK, Stock SP (1997) Techniques in insect nematology. In: Lacey LA (ed) Manual of techniques in insect pathology. Academic Press, New York, pp 281-324
Khatri-Chhetri HB, Timsina GP, Manhandhar HK, Moens M (2011) Potential of Nepalese entomopathogenic nematodes as biocontrol agents against Holotrichia longipennis Blanch. (Coleoptera: Scarabaeidae). J Pest Sci 84:457-469

Koehler PG, Patterson RS, Randy MW (1992) Susceptibility of cockroaches (Duictyoptera: Blattellidae, Blattidae) to infection by Steinernema carpocapsae. J Econ Entomol 85:1184-1187

Kruitbos LM, Heritage S, Hapca S, Wilson MJ (2010) The influence of habitat quality on the foraging strategies of the entomopathogenic nematodes Steinernema carpocapsae and Heterorhabditis megidis. Parasitology 137:303-309

Lacey LA, Rosa JS, Simoes NO, Amaral JJ, Kaya HK (2001) Comparative dispersal and larvicidal activity of exotic and Azorean isolates of entomopathogenic nematodes against Popillia japonica (Coleoptera: Scarabaeidae). Eur J Entomol 98:439-444

Långström B, Day KR (2004) Damage, control and management of weevil pests, especially Hylobius abietis. In: Lieutier F, Day KD, Battisti A, Grégoire J-C, Evans HF (eds) Bark and wood boring insects in living trees in Europe, a synthesis. Springer, Dordrecht, pp 415-444

Leather SR, Day KR, Salisbury ANJ (1999) The biology and ecology of the large pine weevil, Hylobius abietis (Coleoptera: Curculionidae): a problem of dispersal? Bull Entomol Res 89:3-16

Lewis EE, Gaugler R, Harrison R (1992) Entomopathogenic nematode host finding: response to host contact cues by cruise and ambush foragers. Parasitology 105:309-315

Li XY, Cowles RS, Cowles EA, Gaugler R, Cox-Foster DL (2007) Relationship between the successful infection by entomopathogenic nematodes and the host immune response. Int J Parasitol 37:365-374

Loya LJ, Hower AA (2003) Infectivity and reproductive potential of the Oswego strain of Heterorhabditis bacteriophora associated with life stages of the clover root curculio, Sitona hispidulus. J Invertebr Pathol 83:63-72

Mannion CM, Jansson RK (1992) Comparison of ten entomopathogenic nematodes for control of sweet-potato weevil (Coleoptera, Apionidae). J Econ Entomol 85:1642-1650

Pye AE, Burman M (1977) Pathogenicity of the nematode Neoaplectana carpocapsae (Rhabditida, Steinernematidae) and certain microorganisms towards the large pine weevil, Hylobius abietis (Coleoptera, Curculionidae). Ann Entomol Fenn 43:115-119

Pye AE, Burman M (1978) Neoaplectana carpocapsae: infection and reproduction in large pine weevil larvae, Hylobius abietis. Exp Parasitol 46:1-11

Ramos-Rodríguez O, Campbell JF, Ramaswamy SB (2006) Pathogenicity of three species of entomopathogenic nematodes to some major stored-product insect pests. J Stored Prod Res 42:241-252

Richards OW, Davies RG (eds) (1977) Imms' general textbook of entomology: Tenth edition. Volume 1: structure, physiology and development. Chapman and Hall, London

Saleh MME, Draz KAA, Mansour MA, Hussein MA, Zawrah MFM (2009) Controlling the sugar beet beetle Cassida vittata with entomopathogenic nematodes. J Pest Sci 82:289-294 
Schroer S, Yi X, Ehlers R-U (2005) Evaluation of adjuvants for foliar application of Steinernema carpocapsae against larvae of the diamondback moth (Plutella xylostella). Nematology 7:37-44

Sudhaus W (2008) Evolution of insect parasitism in rhabditid and diplogastrid nematodes. Papers dedicated to Prof. Dr Bozidar Curcic. In: Makarov SE, Dimitrijević RN (eds) Advances in arachnology and developmental biology. Institute of Zoology, Faculty of Biology, University of Belgrade, Belgrade, pp 143-161

Torr PS, Wilson MJ, Heritage S (2005) Forestry applications. In: Grewal PS, Ehlers R-U, Shapiro-Ilan DI (eds) Nematodes as biocontrol agents. CABI Publishing, Oxfordshire, pp 281-293

Weslien J (1998) Vad kostar snytbaggeskadorna? (How much does the pine weevil damage cost?) Kunglige Skogs-och Lantbruksakademins Tidskrift 137: 19-22

White GF (1927) A method for obtaining infective nematode larvae from cultures. Science 66:302-303

Williams CD, Dillon AB, Girling R, Griffin CT (2013a) Organic soils promote the efficacy of entomopathogenic nematdoes, with different foraging strategies, in the control of a major forest pest: a meta-analysis of studies to date. Biol Control 65:357-364

Williams CD, Dillon AB, Hennessy R, Mc Namara L, Harvey CD, Griffin CT (2013b) Control of a major pest of forestry, Hylobius abietis, with entomopathogenic nematodes and fungi using eradicant and prophylactic strategies. For Ecol Manage 305:212-222

Xu CX, De Clercq P, Moens M, Chen SL, Han RC (2010) Efficacy of entomopathogenic nematodes (Rhabditida:
Steinernematidae and Heterorhabditidae) against the striped flea beetle, Phyllotreta striolata. BioControl 55:789-797

Yang X, Jian H, Liu Z, Yang H, Yuan J, Quanli Z, Shuangyue L (2003) Evaluation of entomopathogenic nematodes for control of the beetle, Luperomorpha suturalis Chen (Col., Chrysomelidae). Zeitschrift für Angewandte Entomologie 127:377-382

Christopher D. Williams is an applied entomologist with interests in insect conservation and biological control. He has recently been working on the biological control of pine weevil using entomopathogenic nematodes and fungi.

Aoife B. Dillon is the bioinsecticides specialist at BASF and was involved in part of this project when working as the IPM coordinator at the Irish forestry company Coillte.

Darragh Ennis is an entomologist who worked on this project as a $\mathrm{PhD}$ student, investigating behavioural interactions between pine weevils and entomopathogenic nematodes.

Roseanne Hennessy was an MSc student investigating biological control of the vine weevil and pine weevil using combined applications of entomopathogenic nematodes and entomopathogenic fungi.

Christine T. Griffin is a lecturer at Maynooth University with research interest in entomopathogenic nematodes. 